\title{
AUTOAVALIAÇÃO E SEUS DRIVERS DE MUDANÇA INSTITUCIONAL BASEADO NA CAPACIDADE
} ABSORTIVA

\section{RESUMO}

Este artigo tem como objetivo verificar a implantação do SkandiaNavigator como uma ferramenta de gestão em um programa de cursoslatu sensude ensino a distância como fator avaliativo da capacidade absortiva. O SkandiaNavigator se baseia no conceito de capital intelectual para articular recursos, capacidades e competências organizacionais, assim foi utilizado para mensurar a capacidade absortiva da IES no tocante ao curso lato sensu Ead.O SkandiaNavigator consiste em trinta indicadores divididos em sete áreas, sendo o foco financeiro referente aos resultados ocorridos e os focos nos clientes, nos recursos humanos e nos processos voltados ao que ocorre no momento na empresa. Os focos restantessão referentes à capacidade de renovação e de desenvolvimento da organização que permitiriam vislumbrar o futuro da empresa.Utilizou-se drivers de mudança institucional no SkandiaNavigator como forma de mensurar a capacidade absortiva da IES no tocante ao latu sensu de ensino a distância. Ao mensurar nas áreas: financeiras; cliente; processos internos; renovação e desenvolvimento; humanos;capital intelectual; e eficiência do capital intelectual, procurou-se verificar a capacidade da IES para aprender e implementar de novos conhecimentos. Como resultado da pesquisa se considera adequado o uso do SkandiaNavigator é uma ferramenta que pode auxiliar na mensuração da capacidade absortiva da instituição.

Palavras- chave: SkandiaNavigator; Capacidade Absortiva; Indicadores de Desempenho.

\section{SELF-ASSESSMENT AND INSTITUTIONAL CHANGE DRIVERS BASED ON ABSORPTIVE CAPACITY}

\begin{abstract}
This article aims to verify the implementation of SkandiaNavigator as a management tool in a program of courses Ead as evaluative factor of absorptive capacity. The Skandia Navigator is based on the concept of intellectual capital to coordinate resources, skills and organizational skills, and was used to measure the absorptive capacity of the HEIs regarding the broad sense course Ead. O Skandia Navigator consists of thirty indicators divided into seven areas, and the financial focus on the results occurred and the focus on customers, human resources and processes geared to what happens at the moment in the company. The remaining spots are for the renewal of capacity and development of the organization that would allow a glimpse of the future of the company. We used institutional change drivers in Skandia Navigator as a way to measure the absorptive capacity of the HEIs regarding the broad sense of distance learning. In measuring areas: financial; client; internal processes; renewal and development; human, intellectual capital; and efficiency of intellectual capital, sought to verify the ability of HEI to learn and implement new knowledge. As a result of the research is considered appropriate to use the Skandia Navigator is a tool that can assist in measuring the absorptive capacity of the institution.
\end{abstract}

Keywords: Skandia Navigator; Absorptive Capacity; Drivers. 


\section{LA AUTOEVALUACIÓN Y EL CAMBIO INSTITUCIONAL LOS CONTROLADORES DE ABSORCIÓN} BASADO EN LA CAPACIDAD

\section{RESUMEN}

Este artículo tiene por objeto verificar la aplicación de SkandiaNavigator como herramienta de gestión en un programa de aprendizaje a distancia sensude cursoslatu como factor de evaluación de la capacidad de absorción. El SkandiaNavigator se basa en el concepto de capital intelectual para coordinar los recursos, las capacidades y habilidades de organización, y se utilizó para medir la capacidad de absorción de las IES en relación con el sentido amplio supuesto Ead.O SkandiaNavigator consta de treinta indicadores divididos en siete áreas, con el foco relacionadas con los resultados financieros se produjeron y se centra en los clientes, recursos humanos y procesos orientados a lo que sucede en este momento en la empresa. El restantessão se centra con respecto a la capacidad de renovación y desarrollo de la organización que permita una visión del futuro de empresa.Utilizou a los conductores de cambio institucional en SkandiaNavigator como una forma de medir la capacidad de absorción de las IES con respecto a la educación en un sentido amplio la distancia. En las áreas de medición: financiera; al cliente; procesos internos; la renovación y el desarrollo; , El capital intelectual humano; y la eficiencia del capital intelectual, trató de verificar la capacidad de las instituciones de educación superior para aprender y poner en práctica los nuevos conocimientos. Como resultado de la investigación se considera apropiado utilizar el SkandiaNavigator es una herramienta que puede ayudar a medir la capacidad de absorción de la institución.

Palabras clave: Skandia Navigator; La Capacidad de Absorción; Los Indicadores de Rendimiento.

Thiago Coelho Soares ${ }^{1}$ Gisele Mazon ${ }^{2}$

\footnotetext{
${ }^{1}$ Doutor em Administração pela Universidade Federal de Santa Catarina - UFSC. Professor do Curso de Administração da Universidade do Sul de Santa Catarina - UNISUL. Brasil. E-mail: thiago.soares@unisul.br

2 Doutoranda em Administração pela Universidade do Vale do Itajaí - UNIVALI. Brasil. E-mail: gisele.mazon@unisul.br
} 
Autoavaliação e seus Drivers de Mudança Institucional Baseado na Capacidade Absortiva

\section{INTRODUÇÃO}

As organizações universitárias, por sua complexidade, exigem dos seus gestores criatividade na formulação de modelos e abordagens gerenciais que lhes permitam atuar em um contexto complexo caracterizado por objetivos difusos, tecnologia múltipla, liberdade acadêmica, natureza qualitativa do trabalho e grande sensibilidade a fatores ambientais. Para cumprir o seu trabalho, o gestor universitário necessita reunir não só competências técnicas e políticas, mas também habilidades de um artesão ao lidar com as expectativas, intenções, angústias, frustrações e necessidades das pessoas na organização (Meyer Junior \& Meyer, 2004).

A capacidade absortiva está relacionada a capacidade de uma organização para a aprendizagem, a implementação de novos conhecimentos, divulgação de novos conhecimentos internamente e fazendo uso de novos recursos, incluindo novas tecnologias. A capacidade de absorção é uma função de recursos existentes da organização, o conhecimento tácito e explícito existente, rotinas internas, competências de gestão e cultura (Gray, 2006). Assim, desenvolver e manter a capacidade absortiva é necessário para manter a sobrevivência da organização a longo prazo, pois dessa forma a base de conhecimento da empresa é complementada, reforçada e reorientada constantemente (Lane \& Koka \& Pathak, 2002).

A avaliação de desempenho das organizações é uma atividade essencial na gestão, trazendo, neste milênio, novos desafios aos gestores ante a dinâmica do mundo dos negócios. Essa nova perspectiva social exigiu um novo olhar sobre o que significa avaliar o desempenho organizacional. Avaliar o desempenho consiste em atribuir valor àquilo que uma organização considera importante diante de seus objetivos estratégicos (Nascimento, et al, 2011).

Para viabilizar o processo de criação instrumentos de avaliação, a partir da década de 1990, o Ministério de Educação e Cultura (MEC) vem desenvolvendo suporte teórico-metodológico. Em 2004, o Sistema Nacional de Avaliação da Educação Superior (SINAES) propôs diretrizes voltadas à pluralidade de aspectos relativos ao universo acadêmico, possibilitando às Instituições construírem instrumentos de avaliação que detectassem as fragilidades e as potencialidades institucionais para a melhoria da qualidade da oferta educacional em todos os sentidos (Batista, et al, 2013).

A complexidade da organização social vigente, caracterizada pela incerteza, pelo reconhecimento do caráter instável do conhecimento e pelas discussões acerca da legitimidade dos paradigmas vigentes impõe um redimensionamento do sentido de avaliação cristalizado no âmbito das intuições educacionais. As pressões vêm de duas direções: de um lado, o mercado provoca tensões concernentes aos objetivos e à constituição dessas intuições; de outro, as políticas educacionais do Estado criam mecanismos para que as autoavaliações institucionais sejam instrumentos de gestão (Batista, et al, 2013).

Desta forma o objetivo do artigo é verificar a implantação do SkandiaNavigator como uma ferramenta de gestão em um programa de cursoslatu sensude ensino a distância como fator avaliativo da capacidade absortiva.

Este trabalho se justifica na medida em que, Lima et al (2013) afirmam que principalmente para uma IES, construir e manter um processo avaliativo que seja formativo e esteja em constante desenvolvimento necessita de um sistema que tenha em sua gênese elementos oriundos da comunidade acadêmica e não algo que venha "pronto" de cima para baixo. Bem como, conforme Crispim e Lugoboni (2012) o descompasso entre oferta e demanda gerou aumento de $160 \%$ no número de vagas ociosas entre 2002 e 2008. Esta tendência redundou na queda de $34 \%$ na relação candidato por vaga, que em 2002 era 2,81 , e diminui para 1,85 em 2008, e em um grande acirramento da concorrência entre as IES. Assim, em um ambiente institucional cada vez mais competitivo, os gestores buscam ferramentas para controlar suas operações e suas estratégias. Neste sentido, muitos estudos vêm sendo realizados na academia sobre o gerenciamento por meio de modelos de avaliação de desempenho organizacional, que são ferramentas utilizadas para realizar esse controle.

Ressalta-se também que desenvolver instrumentos de mensuração de capacidade absortiva se justifica em função de dois motivos: pode-se propor práticas de intervenção organizacional mediante diagnóstico e; é possível comparar populações de organizações, compreendendo realidades coletivas. (Jansen \& Van Den Bosch \& Volberda, 2005; Fosfuri \& Tribó, 2008; Murovec \& Eprodan, 2009; Versiani et al, 2010).

\section{CAPACIDADE ABSORTIVA}

Desde a publicação do artigo seminal de Cohen e Levinthal (1990), o conceito da capacidade de absorção tem despertado grande interesse da comunidade científica e tem sido utilizado para explicar uma série de fenômenos organizacionais (Lane et al, 2002). Cohen e Levinthal (1990) tratam a capacidade de absorção como capacidade de uma organização de perceber no ambiente externo, novas informações de alto valor e sua posterior assimilação e aplicação, pois constituem as características críticas para a inovação nas organizações (Cohen \& Levinthal, 1990).

Zahra e George (2002) confirmam que a capacidade absortiva é capaz de explicar vários fenômenos organizacionais. Essa capacidade de absorção é definida como rotinas e processos organizacionais por meio dos quais uma organização 
adquire, assimila, transforma e aplica conhecimentos

(Zahra \& George, 2002).

Quadro 1 - elementos da Capacidade Absortiva

\begin{tabular}{|c|c|c|c|}
\hline & & & \\
\hline $\begin{array}{llr}\begin{array}{l}\text { Habilidade } \\
\text { organização }\end{array} & \text { em } \\
\text { identificar e } & \text { obter } \\
\text { conhecimento por } & \text { meio } \\
\text { de recursos externos. }\end{array}$ & 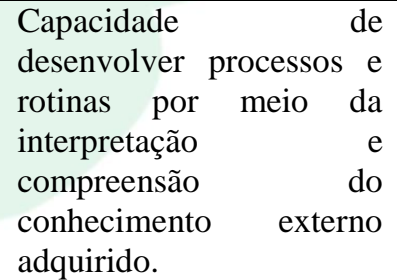 & 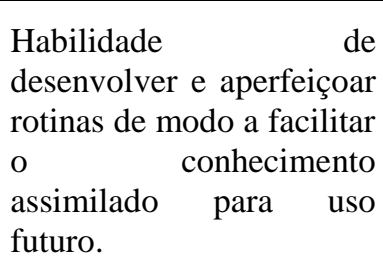 & $\begin{array}{lr}\text { Capacidade } & \text { para } \\
\text { melhorar, expandir-se e } \\
\text { usar suas rotinas e } \\
\text { competências para criar } \\
\text { algo } & \text { novo, } \\
\text { transformando-o r em } \\
\text { conhecimento. }\end{array}$ \\
\hline
\end{tabular}

Fonte: adaptado de Flaten et all, 2011.

Os elementos 'aquisição' e 'assimilação, segundo Zahra e George (2002), tratam-se de capacidades potenciais e 'transformação' e 'exploração' tratam-se de capacidades realizadas.

Figura 1 - Capacidade Absortiva

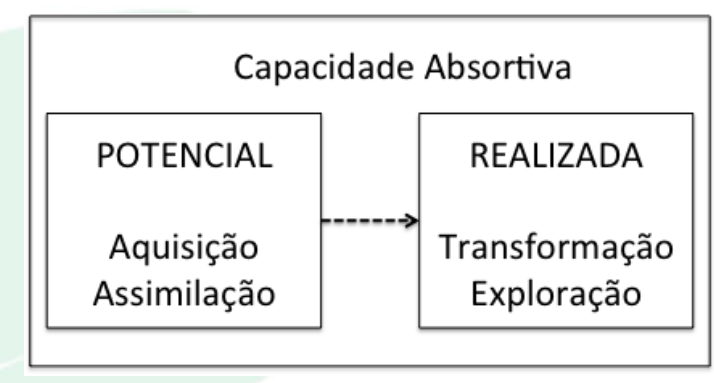

Fonte: Adaptado de Zahra e George, 2002

Wang e Ahmed (2007) afirmam que a capacidade de absorção das empresas é fundamental para o sucesso em face da mudança tecnológica externa. As empresas com maior capacidade de absorção experimentam um processo de adoção relativamente eficiente levando a resultados positivos de desempenho, enquanto as empresas com menor capacidade de absorção encontram dificuldades significativas. A capacidade de absorção é um diferencial entre as empresas e é exibida em vários aspectos como por exemplo o resultado apresentado para a indústria petrolífera:

1) demonstrar um compromisso de longo prazo dos recursos em face da incerteza (vs. compromisso limitado a curto prazo e invertida no primeiro sinal de fracasso);

2) aprender com vários parceiros e próprias pesquisas e experiências e desenvolver conhecimento em primeira mão das novas tecnologias (vs. imitação competitiva e conhecimento de segunda mão);

3) analisar cuidadosamente a nova tecnologia de perfuração e compartilhar informações dentro de equipes multidisciplinares (vs. análise superficial e estrutura funcional);
4) desenvolver e utilizar tecnologias complementares (vs. há tecnologias complementares utilizados); e,

5) possuem um alto nível de conhecimentos e competências em áreas relevantes para a aplicação da nova tecnologia.

Wang e Ahmed (2007) afirmam que a capacidade das empresas para adquirir novos conhecimentos do ambiente externo e assimilá-lo com o conhecimento existente e criar novos conhecimentos é um fator importante das capacidades dinâmicas em vários setores. Quanto maior a empresa demonstra sua capacidade de absorção, mais ela exibe capacidades dinâmicas. A capacidade de absorção é um constructo multidimensional e existem quatro fatores componentes do construto capacidade de absorção: aquisição de conhecimento, assimilação, transformação e exploração, no entanto, ainda faltam estudos empíricos que validem um constructo multidimensional da capacidade de absorção.

Os resultados do estudo de Lichtenthaler (2009) enfatizam a natureza multidimensional da capacidade absortiva. Os resultados ajudam a explicar as discrepâncias em lucrar com o conhecimento externo. Além disso, os resultados sublinham a importância de capacidades dinâmicas em contextos 
caracterizados por altos níveis de turbulência tecnológica e de mercado.A capacidade absortiva influencia a inovação, o desempenho dos negócios, transferência de conhecimento intra-organizacional e a aprendizagem interorganizacional Assim, facilita o acúmulo de conhecimento e sua posterior utilização. Isto porque, explorando conhecimentos adquiridos externamente geralmente requer converter seu conteúdo em uma forma utilizável (Flatten, et al , 2011). Kor e Mesko (2013) trazem a relação entre a capacidade dinâmica dos CEOs e Executivos Seniors e como estas capacidades influenciam a capacidade asbortiva das equipes. Por consequência, isto influencia no resultado da empresa.

$\mathrm{Ng}$ (2007) apresenta que a diversificação não relacionada de negócios é explicada por três pilares, que consistem em sua força de capacidades dinâmicas, a capacidade absortiva, e laços fracos. O papel dos três pilares é descobrir novas aplicações de recursos ou usos em condições de falha de mercado que são caracterizadas por mercados incompletos. Uma nova característica deste modelo é que uma organização pode se diversificar de forma mais ampla do que o previsto por Penrose (1959) e outras abordagens baseadas em recursos modernos (Teece et al., 1997). Além disso, a diversificação independente possa ser benéfica.

Rothaermel e Alexandre (2009) sugerem que a obtenção e manutenção de uma combinação de terceirização de tecnologia interna-externa, somada a capacidade absortiva pode atingir melhor desempenho, e ainda ser considerado uma capacidade dinâmica da empresa, porque ela é o reflexo da capacidade de uma empresa de integrar, construir, e reconfigurar competências internas e externas para enfrentar ambientes que mudam rapidamente. A literatura sugere que as firmas necessitam e precisam utilizar tanto desenvolvimento interno e recursos externos ao longo do tempo (Capron \& Mitchell, 2008).

Lichtenthaler e Lichtenthaler (2009) aprofundam os estudos sobre capacidade dinâmica investigando sobre gestão do conhecimento, capacidade absortiva e capacidades dinâmicas para se chegar a uma perspectiva integradora, que considera a exploração, retenção e aproveitamento do conhecimento dentro e fora dos limites de uma empresa. Ao complementar o conceito de capacidade absortiva, os autores avançam em direção a uma estrutura baseada em capabilidade de processos de inovação aberta. Os autores chegaram a identificação de seis "capacidades de conhecimento" como capacidades críticas de uma empresa: inventivos, absortivos, transformativos, conectivos, inovativos e capacidade de tirar proveito econômico de conhecimentos externos.

\subsection{Auto-avaliação institucional}

O desenvolvimento da "avaliação das instituições" corresponde ao primeiro eixo temático do
SINAES, e seu principal objetivo é verificar a constituição das IES, sua capacidade de atendimento à comunidade acadêmica de forma geral (Maba \& Marinho, 2012).

A avaliação é uma realidade nas instituições de ensino superior do país. Faz-se presente em todas as atividades de ensino, pesquisa e extensão, e mesmo nas práticas administrativas, de uma Universidade. A autoavaliação institucional constitui uma análise interna que visa conhecer a instituição como um todo, considerando a sua dinâmica interna, ou seja, as condições que contribuíram para que aquele resultado fosse obtido. Assim, potencialidades e fragilidades passam a ser consideradas como referências para novas experiências, estratégias e propostas que representem novos passos na criação de uma cultura de avaliação, cuja finalidade seja a construção de uma universidade humana e humanizadora (Batista, et al, 2013).

O objetivo da auto-avaliação é criar uma atmosfera para que a comunidade acadêmica forme coletivamente uma consciência dos indicadores que estão contribuindo para a construção do presente e do futuro institucional e daqueles que não estão correspondendo ao pleno andamento das atividades (Lehfeld et al, 2010).

Lima et al (2012) procuraram analisar a relação entre as aplicações de Balanced ScoreCard (BSC) em IES com os indicadores do SINAES, tentando identificar uma forma de auto-avaliação institucional. Observou-se que existe uma maior confluência entre as perspectivas dos BSC das IES do exterior com o SINAES do que as perspectivas dos BSCs da IES nacionais. Isto se confirma com a informação que as IES do exterior apresentam sete perspectivas do SINAES em sua auto-avaliação, enquanto as IES nacionais apresentam apenas cinco perspectivas do SINAES em seus BSCs. No exterior existem as perspectivas: política para o ensino, a pesquisa, a pósgraduação, a extensão; comunicação com a sociedade; as políticas de pessoal; organização e gestão da instituição; planejamento e avaliação; políticas de atendimento aos estudantes; e sustentabilidade financeira. Já no Brasil apenas: comunicação com a sociedade; organização e gestão da instituição; planejamento e avaliação; políticas de atendimento aos estudantes; e sustentabilidade financeira. Os autores indicam também que as perspectivas do SINAES: a missão e o plano de desenvolvimento institucional; a responsabilidade social da instituição; e infra-estrutura física não estão presentes diretamente nos BSCs das IES nacionais e internacionais.

Com relação aos indicadores presentes na gestão das IES, um dos pressupostos imagináveis consistia em que estas entidades focam de forma demasiada em indicadores financeiros e nas determinações exigidas pelo Ministério da Educação (MEC). Este pressuposto foi negado, pois foi constatado que os aspectos mais importantes para as IES são a gestão de sua demanda e de seus alunos (Crispim \& Lugoboni, 2012). 
Frederico e Martins (2012) identificamque os elementos dos Sistemas de Medição de Desempenho se modificam conforme a maturidade da instituição aumenta. Complementando, Soares et al (2012) considera adequado o uso do Skandia Navigator de maneira a planejar e controlar melhor as ações das instituições universitárias, assim sendo uma ferramenta possível de ser utilizada como auto-avaliação.

\subsection{Skandia Navigator}

Lima et al (2011) atenta à necessidade de novasabordagens econômicas para mensurar o desempenho das corporações, utilizando ocapital intelectual como fator principal de produção. Isto porque os ativos intangíveis agregam valor de maneira sustentada. A visão de se criar valor é compartilhada pelas áreas de finançase estratégias.

Organizações que iniciaram a medir o CI e publicar suas experiências bem sucedidas nesse campo, acabaram por obter um diferencial no mercado e assim atingiram vantagem competitiva. Exemplo disso é a empresa sueca Skandia (Vargas, et al, 2008).

Assim, Edvinsson e Malone em 1998 buscaram unir diversos indicadores - tanto econômicos e financeiros quantoqualitativos - e, através de pesos atribuídos a esses indicadores, relacionar oresultado à performance da empresa e criaram o Skandia Navigatorou Navegador de Capital Intelectual (Lima et al, 2011).

O Skandia Navigator apresenta três perspectivas diferentes de análise, o foco financeiro (passado), foco nos clientes, nos recursos humanos e nos processos (presente) e foco na capacidade de renovação e de desenvolvimento organizacional (futuro). $\mathrm{Na}$ sequência será detalhada a ferramenta.

A partir da Gestão do Conhecimento, no início dos anos noventa, a Skandia, uma empresa sueca criou uma ferramenta de avaliação de desempenho denominada Skandia Navigator. Esta ferramenta passou a orientar a mensuração do desempenho na organização e se tornou uma das forças-motrizes no movimento do capital intelectual, porque permitem identificar os resultados para a empresa, decorrentes de uma estratégia baseada na criação de conhecimento (Hourneaux Junior, 2005).

O Navigator "fornece uma imagem equilibrada do capital financeiro e intelectual" (Von Krogh et al, 2001, p. 118). O Navegador consiste em indicadores divididos em cinco áreas, sendo o foco financeiro referente aos resultados ocorridos e os focos nos clientes, nos recursos humanos e nos processos voltados ao que ocorre no momento na empresa. $\mathrm{O}$ foco restante é referente à capacidade de renovação e de desenvolvimento da organização que permitiriam vislumbrar o futuro da empresa. (Hourneaux Junior, 2005).

Cada um dos focos apresenta os chamados indicadores CI, que "traduzem cada foco em resultados utilizáveis, com a atenção voltada, sobretudo à posição estratégica", possibilitando o uso estratégico do conhecimento (Von Krogh et al, 2001, p. 118), conforme ilustrado na figura 2 .

Figura 2 - SkandiaNavigator
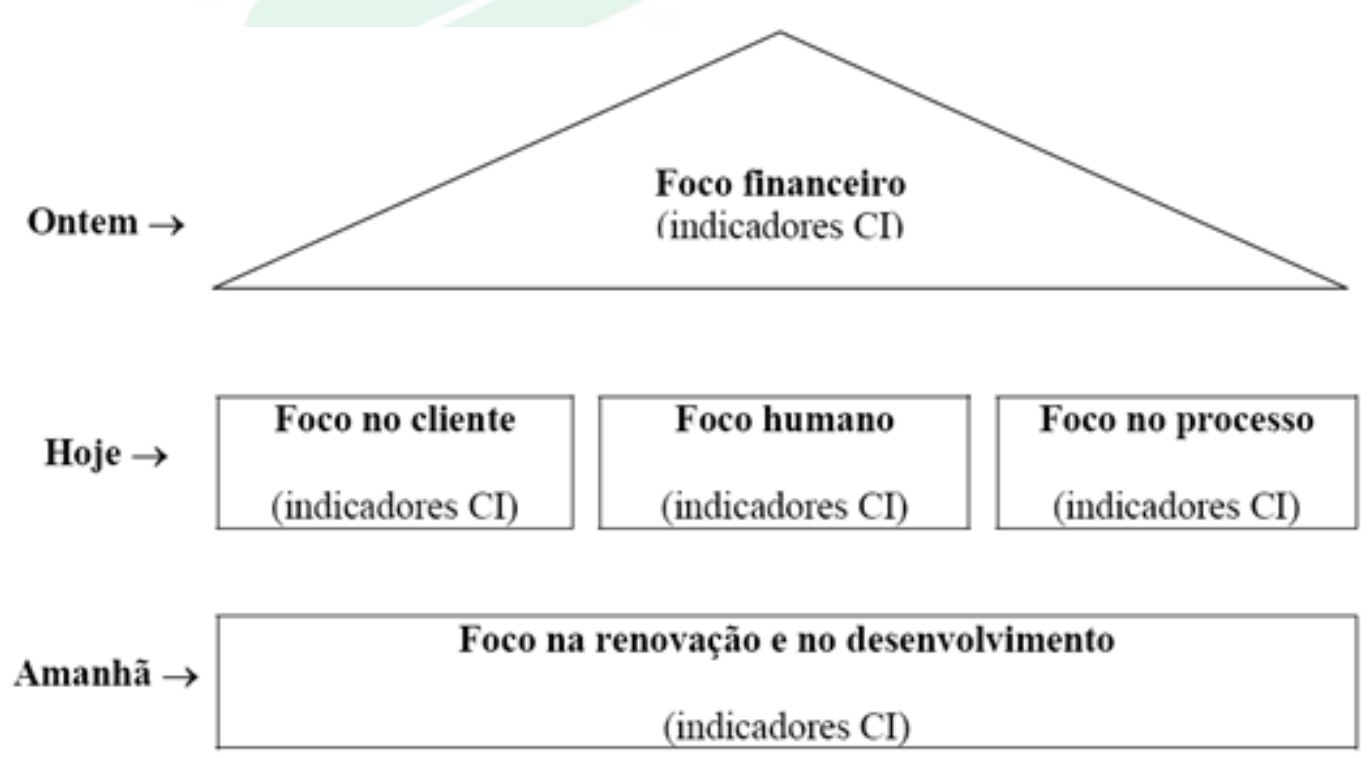

Fonte: Hourneaux Junior, 2005 
O Skandia Navigator produz um relatório de avaliação do capital intelectual cujas medidas são organizadas segundo cinco dimensões: financeira, do cliente, dos processos, da renovação e desenvolvimento e humana (Malavski \& Lima \& Costa, 2010).

Leif Edvinsson foi o criador do Navigatore diretor, posteriormente vice-presidente, da área de capital intelectual da Skandia (Von Krogh et al, 2001, p. 117-118), informa as três funções da ferramenta:

- Perscrutar as mensurações: o Navigator deve indicar a posição, a direção e a velocidade da organização, formando um conjunto correto de medições, agrupadas coerentemente em categorias, que formam um todo também coerente (Hourneaux Junior, 2005);

- Olhar para o alto, em direção a medidas mais abrangentes de valor: a operacionalização das medidas deve permitir uma abstração de um ponto de vista mais global, facilitando uma análise da organização e a comparação com outras (Hourneaux Junior, 2005);

- Olhar para fora, em direção ao usuário: apesar das dificuldades que isso represente, dada a contabilidade tradicional (Hourneaux Junior, 2005).

O Navegador Skandia, contém certos valores de sucesso, identificados pela equipe da empresa, que deveriam ser maximizados e incorporados à estratégia organizacional.

Edvinsson e Malone (1998) explicam que o valor monetário do capital intelectual (o capital intelectual é premissa para o navegador) é uma medida absoluta que representa o valor do Capital Intelectual da organização.

Soares et al (2012) utilizou um modelo de mensuração do capital intelectual por meio do Skandia Navigator, por meio dos indicadores apresentados a seguir.

Quadro 2 - Indicadores da Mensuração do Capital Intelectual

\begin{tabular}{|l|}
\hline \\
\hline - Indicadores financeiros: \\
\hline - Receita operacional líquida \\
\hline - Receita/disciplina \\
\hline - Despesas diretas do curso/despesas administrativas \\
\hline - Margem de Lucro \\
\hline - Indicadores de cliente: \\
\hline - Participação das vendas na pós-graduação da instituição \\
\hline - Número de clientes \\
\hline - Número de clientes internos \\
\hline - Número com desconto \\
\hline - Número de clientes com desconto/número de cliente \\
\hline - Indicadores de processos: \\
\hline - Despesas administrativas/receita total \\
\hline - Despesas administrativas/professores \\
\hline - Satisfação dos alunos \\
\hline - Desempenho corporativo/meta de qualidade \\
\hline - Custos anuais por aluno \\
\hline - Custos diretos por aluno \\
\hline - Indicadores de renovação e desenvolvimento: \\
\hline - Despesas com o desenv. de competências/professor \\
\hline - Índice de satisfação dos professores \\
\hline - Indicadores humanos: \\
\hline • Número de professores \\
\hline
\end{tabular}


Autoavaliação e seus Drivers de Mudança Institucional Baseado na Capacidade Absortiva

\begin{tabular}{|l|}
\hline - Número de turmas \\
\hline - Rotatividade dos professores por ano \\
\hline - Capital intelectual: \\
\hline - Investimento em TI \\
\hline - Investimento no suporte aos alunos \\
\hline - Investimento no treinamento de alunos \\
\hline - Eficiência do capital intelectual: \\
\hline - Participação no mercado interno (\%) \\
\hline - Índice de satisfação dos clientes (\%) \\
\hline - Índice de motivação dos professores (\%) \\
\hline - Índice de investimento em TI/receita total (\%) \\
\hline - Índice de horas de treinamento (\%) \\
\hline - Desempenho/meta de qualidade (\%) \\
\hline - Retenção dos empregados (\%) \\
\hline
\end{tabular}

Fonte: Soares, et al (2012)

Edvinsson e Malone (1998) explicam que cada foco apresentado no modelo do Skandinavia Navigator representa as áreas nas quais uma empresa focaliza sua atenção, e de onde provém o valor de seu capital intelectual.

Viedma Marti (2007) salienta que o Skandia Navigator por ser orientado para a criação de valor, não possui o dinamismo e a flexibilidade necessária na turbulência do ambiente moderno. Em contrapartida, Samia et al (2012) afirma que o Skandia Navigator é considerado um bom sistema de medição de desempenho para incentivar o princípio da melhoria contínua, bem como incentiva a preservação das experiências anteriores sobre se os documentos ou material,isto é explicado pelo avanço do Skandia Navigator em capital intelectual.

\section{METODOLOGIA}

Primeiramente foi desenvolvida a aplicação da metodologia Skandia Navigator para a mensuração do desempenho de um conjunto de cursos de pósgraduação Lato Sensu em modalidade a distância. A aplicação desta metodologia pode ser interpretada como uma forma de auto-avaliação do desempenho dos cursos.

Para este estudo de caso às técnicas de coleta de dados, foram divididas em duas etapas: pesquisa bibliográfica e, pesquisa documental.

Da pesquisa Bibliográfica chegou-se ao "Navegador de Capital Intelectual" composto de trinta e um indicadores divididos em sete focos, sendo indicadores financeiros;indicadores de cliente;indicadores de processos;indicadores de renovação e desenvolvimento;indicadores de recursos humanos;capital intelectual; e eficiência do capital intelectual. Este conjunto de sete focos corresponde a versão do Skandia Navigator a ser adotada nesta pesquisa.

Da pesquisa documental, obteve-se relatórios gerenciais da universidade, que possibilitou a mensuração das sete áreas por meio dos trinta e um drivers.

Num segundo momento, após a aplicação do estudo de caso, a análise dos dados foi realizada com base em dois dos elementos da teoria de Capacidade Absortiva: transformação e exploração. Estes dois elementos são considerados por Zahra e George (2002) como realizáveis. Como os drivers da avaliação de desempenho organizacional mensuram ações concretas, ou já realizadas, torna-se difícil a mensuração, por esta metodologia, dos elementos de aquisição e assimilação, que são elementos potenciais, segundo Zahra e George (2002).

Para a analise dos dados, utilizou-se a técnica de analise de conteúdo, para o entrelace conceitual dos sete focos do Skandia Navigator, com os dois elementos realizáveis da Capacidade Absortiva.

No quadro a seguir, estão expressas as definições de Transformação e Exploração da Capacidade Absortiva com as aplicabilidades dos sete focos do Skandia Navigator. 
Quadro 3 - Entrelace conceitual dos sete focos do Skandia Navigator com os dois elementos realizáveis da Capacidade Absortiva.

\begin{tabular}{|c|c|}
\hline $\begin{array}{l}\text { Transformação - Habilidade de desenvolver e } \\
\text { aperfeiçoar rotinas de modo a facilitar o conhecimento } \\
\text { assimilado para uso futuro. }\end{array}$ & $\begin{array}{l}\text { s para criar algo novo, } \\
\text { to. }\end{array}$ \\
\hline & \\
\hline $\begin{array}{l}\text { Focos clientes, nos recursos hur } \\
\text { processos - são voltados para o que } \underline{\mathrm{oc}} \\
\text { na empresa. }\end{array}$ & $\begin{array}{l}\text { intelectual e eficiência do capital intelectual - } \\
\text { referem-se à capacidade de renovação e de } \\
\text { desenvolvimento da organização que permitiriam } \\
\text { vislumbrar o futuro da empresa }\end{array}$ \\
\hline
\end{tabular}

Fonte: Os autores.

Na primeira coluna está o entrelace para o elemento 'transformação' da Capacidade Absortiva e na segunda coluna para o elemento 'exploração'. Em cada célula existem termos sublinhados, que evidenciam o relacionamento conceitual dos conceitos.

\section{APRESENTAÇÃO DOS RESULTADOS}

O foco financeiro refere-se aos resultados ocorridos, ou seja, findados. Os focos no clientes, nos recursos humanos e nos processos são voltados para o que ocorre atualmente na empresa. Os focosIndicadores de renovação e desenvolvimento, capital intelectual e eficiência do capital intelectualreferem-se à capacidade de renovação e de desenvolvimento da organização que permitiriam vislumbrar o futuro da empresa.

Os drivers utilizados foram adotados do modelo de Soares et al (2012) com o modelo avaliativo de Malavski, et al (2010), chegou-se aos valores apresentados a seguir.

Quadro 4 - Indicadores da Mensuração do Capital Intelectual curso Lato Sensu

\begin{tabular}{|c|c|c|c|c|c|c|}
\hline & & Ano 01 & & Ano 02 & \multicolumn{2}{|c|}{$\Delta$ do indicador } \\
\hline \multicolumn{7}{|l|}{ - Indicadores financeiros: } \\
\hline - Receita operacional líquida & \multicolumn{2}{|c|}{$\mathrm{R} \$ 1.019 .431,20$} & \multicolumn{2}{|c|}{$\mathrm{R} \$ 1.031 .869,90$} & \multicolumn{2}{|c|}{$\mathrm{R} \$ \quad 12.438,70$} \\
\hline - Receita/disciplina & $\mathrm{R} \$$ & $19.604,45$ & $\mathrm{R} \$$ & $19.661,18$ & $\mathrm{R} \$$ & 56,73 \\
\hline - Despesas diretas do curso/despesas administrativas & \multicolumn{2}{|r|}{1,3} & \multicolumn{2}{|r|}{2,54} & \multicolumn{2}{|r|}{1,24} \\
\hline - Margem de Lucro & \multicolumn{2}{|r|}{$64,91 \%$} & \multicolumn{2}{|c|}{1,3023} & \multicolumn{2}{|c|}{$65,32 \%$} \\
\hline \multicolumn{7}{|l|}{ - Indicadores de cliente: } \\
\hline - Participação das vendas na pós-graduação da instituição & \multicolumn{2}{|r|}{$23,00 \%$} & \multicolumn{2}{|c|}{$24,22 \%$} & \multicolumn{2}{|c|}{$1,22 \%$} \\
\hline • Número de clientes & \multicolumn{2}{|r|}{320} & \multicolumn{2}{|r|}{333} & \multicolumn{2}{|r|}{13} \\
\hline - Número de clientes internos & \multicolumn{2}{|r|}{15} & \multicolumn{2}{|r|}{27} & \multicolumn{2}{|r|}{12} \\
\hline - Número com desconto & \multicolumn{2}{|r|}{180} & \multicolumn{2}{|r|}{175} & \multicolumn{2}{|r|}{-5} \\
\hline - Número de clientes com desconto/número de cliente & \multicolumn{2}{|r|}{$56,25 \%$} & \multicolumn{2}{|c|}{$52,55 \%$} & \multicolumn{2}{|c|}{$-3,70 \%$} \\
\hline \multicolumn{7}{|l|}{ - Indicadores de processos: } \\
\hline - Despesas administrativas/receita total & \multicolumn{2}{|r|}{$15,26 \%$} & \multicolumn{2}{|c|}{$12,93 \%$} & \multicolumn{2}{|c|}{$-2,33 \%$} \\
\hline - Despesas administrativas/professores & $\mathrm{R} \$$ & $6.841,39$ & $\mathrm{R} \$$ & $6.793,55$ & $-\mathrm{R} \$$ & 47,84 \\
\hline - Satisfação dos alunos & \multicolumn{2}{|r|}{$90,00 \%$} & \multicolumn{2}{|c|}{$90,00 \%$} & \multicolumn{2}{|c|}{$0,00 \%$} \\
\hline - Desempenho corporativo/meta de qualidade & \multicolumn{2}{|r|}{$94,00 \%$} & & $95,55 \%$ & & $1,55 \%$ \\
\hline - Custos anuais por aluno & $\mathrm{R} \$$ & $1.117,97$ & $\mathrm{R} \$$ & $1.094,63$ & $-\mathrm{R} \$$ & 23,34 \\
\hline - Custos diretos por aluno & & 631,84 & & 629,16 & & $-2,68$ \\
\hline - Indicadores de renovação e desenvolvimento: & & & & & & \\
\hline - Despesas com o desenv. de competências/professor & & $8.400,00$ & $\mathrm{R} \$$ & $9.640,00$ & $\mathrm{R} \$$ & $1.240,00$ \\
\hline
\end{tabular}


Autoavaliação e seus Drivers de Mudança Institucional Baseado na Capacidade Absortiva

\begin{tabular}{|c|c|c|c|}
\hline • Índice de satisfação dos professores & $87,50 \%$ & $89,75 \%$ & $2,25 \%$ \\
\hline \multicolumn{4}{|l|}{ - Indicadores humanos: } \\
\hline - Número de professores & 24 & 24 & 0 \\
\hline - Número de turmas & 52 & 52 & 0 \\
\hline - Rotatividade dos professores por ano & 3 & 2 & -1 \\
\hline - Número médio de anos de serviços com a empresa & 10 & 11 & 1 \\
\hline \multicolumn{4}{|l|}{ - Capital intelectual: } \\
\hline - Investimento em TI & $52.356,55$ & $\mathrm{R} \$ \quad 51.802,59$ & 553,96 \\
\hline - Investimento no suporte aos alunos & $31.544,12$ & $\mathrm{R} \$ \quad 30.289,24$ & $-\mathrm{R} \$ \quad 1.254,88$ \\
\hline - Investimento no treinamento de alunos & $6.400,00$ & $\mathrm{R} \$ \quad 6.600,00$ & 200,00 \\
\hline \multicolumn{4}{|l|}{ - Eficiência do capital intelectual: } \\
\hline • Participação no mercado interno (\%) & $23,00 \%$ & $21,75 \%$ & $-1,25 \%$ \\
\hline - Índice de satisfação dos clientes (\%) & $90,00 \%$ & $90,00 \%$ & $0,00 \%$ \\
\hline - Índice de motivação dos professores (\%) & $87,50 \%$ & $89,75 \%$ & $2,25 \%$ \\
\hline - Índice de investimento em TI/receita total (\%) & $5,15 \%$ & $5,10 \%$ & $-0,05 \%$ \\
\hline - Índice de horas de treinamento (\%) & $13,33 \%$ & $15,33 \%$ & $2,00 \%$ \\
\hline - Desempenho/meta de qualidade (\%) & $94,00 \%$ & $94,00 \%$ & $0,00 \%$ \\
\hline • Retenção dos empregados (\%) & $87,50 \%$ & $91,67 \%$ & $4,17 \%$ \\
\hline
\end{tabular}

Fonte: Autores

Além da análise da variação em termos absolutos, é possível também adotar a variação em termos percentuais.

Quadro 5 - Variação da Mensuração do Capital Intelectual curso Lato Sensu

\begin{tabular}{|l|c|}
\hline & $\Delta \%$ do indicador \\
\hline - Indicadores financeiros: & \\
\hline • Receita operacional líquida & $1,22 \%$ \\
\hline • Receita/disciplina & $0,29 \%$ \\
\hline • Despesas diretas do curso/despesas administrativas & $95,38 \%$ \\
\hline • Margem de Lucro & $100,63 \%$ \\
\hline - Indicadores de cliente: & \\
\hline • Participação das vendas na pós-graduação da instituição & $5,30 \%$ \\
\hline • Número de clientes & $4,06 \%$ \\
\hline • Número de clientes internos (alunos que são funcionários da universidade) & $80,00 \%$ \\
\hline • Número com desconto & $-2,78 \%$ \\
\hline • Número de clientes com desconto / número de cliente & $-6,57 \%$ \\
\hline - Indicadores de processos: & \\
\hline - Despesas administrativas/receita total & $-15,27 \%$ \\
\hline - Despesas administrativas/professores & $-0,70 \%$ \\
\hline • Meta de qualidade corporativa (satisfação dos alunos) & $0,00 \%$ \\
\hline • Desempenho corporativo/meta de qualidade & $1,65 \%$ \\
\hline • Custos anuais por aluno & $-2,09 \%$ \\
\hline • Custos diretos por aluno & $-0,42 \%$ \\
\hline
\end{tabular}


Autoavaliação e seus Drivers de Mudança Institucional Baseado na Capacidade Absortiva

\begin{tabular}{|l|c|}
\hline - Indicadores de renovação e desenvolvimento: & \\
\hline • Despesas com o desenvolvimento de competências/professor & $14,76 \%$ \\
\hline • Índice de satisfação dos professores & $2,57 \%$ \\
\hline - Indicadores humanos: & \\
\hline • Número de professores & $0,00 \%$ \\
\hline - Número de turmas & $0,00 \%$ \\
\hline • Rotatividade dos professores por ano & $-33,33 \%$ \\
\hline • Número médio de anos de serviços com a empresa & $10,00 \%$ \\
\hline - Capital intelectual: & \\
\hline • Investimento em TI & $-1,06 \%$ \\
\hline • Investimento no suporte aos alunos & $-3,98 \%$ \\
\hline • Investimento no treinamento de alunos & $3,13 \%$ \\
\hline - Eficiência do capital intelectual: & \\
\hline • Participação no mercado interno (\%) & $-5,43 \%$ \\
\hline • Índice de satisfação dos clientes (\%) & $0,00 \%$ \\
\hline • Índice de motivação dos professores (\%) & $2,57 \%$ \\
\hline • Índice de investimento em TI/receita total (\%) & $-0,97 \%$ \\
\hline • Índice de horas de treinamento (\%) & $15,00 \%$ \\
\hline • Desempenho/meta de qualidade (\%) & $0,00 \%$ \\
\hline$\bullet$ Retenção dos empregados (\%) & $4,76 \%$ \\
\hline
\end{tabular}

Fonte: Autor

Considerando os indicadores apresentados $\mathrm{e}$ suas variações com efeito positivo do Ano 01 para o Ano 02, pode-se inferir que a empresa gerou novas competências, fortalecendo, portanto, as competências apresentadas na organização.

Considerando as três funções do Skandia Navigator: Perscrutar as mensurações, Olhar para o alto, em direção a medidas mais abrangentes de valor e Olhar para fora, em direção ao usuário foram atendidas pelos drivers utilizados.

- Perscrutar as mensurações: o Navigator apresentou trinta indicadores que formaram um conjunto de medições e que estavam agrupadas coerentemente em categorias, que formou um todo coerente, ou seja, abrangeu o era preciso para avaliar o curso Latu Sensu Ead;

- Olhar para o alto, em direção a medidas mais abrangentes de valor: indicadores abrangentes e que permitem uma avaliação com outras instituições que utilizem os mesmos drivers;

- Olhar para fora, em direção ao usuário: procurou-se identificar drivers que fossem capazes de mensurar a capacidade da empresa de absorver conhecimento.
A aplicação prática permitiu avaliar mais objetivamente da importância estratégica dos recursos, capacidade e desenvolvimento de competências organizacionais. Assim, permitiu-se elaborar uma autoavaliação da IES por meio de drivers de mudança institucional que eram capazes de mensurar a capacidade absortiva do objeto de estudo desta pesquisa.

Utilizou-se os indicadores supracitados no Skandia Navigator como forma de mensurar a capacidade absortiva da IES no tocante ao latu sensu de ensino a distância. Ao mensurar nas áreas: financeiras; cliente; processos internos; renovação e desenvolvimento; humanos;capital intelectual; e eficiência do capital intelectual, procurou-se verificar a capacidade da IES para aprender e implementar de novos conhecimentos.

Considerando a capacidade absortiva como a capacidade de uma organização para aprender, implementar conhecimentos, divulgar internamente este novo conhecimento e fazer uso de novos recursos para atender este novo conhecimento, estabeleceu-se que os drivers do Skandia Navigator correspondem a dois elementos da capacidade absortiva. O elemento transformação e mensurado pelos drivers dos focos financeiro, clientes, nos recursos humanos e nos processos. Já o elemento exploração é mensurado pelos drivers renovação e desenvolvimento, capital intelectual e eficiência do capital intelectual. 
Quadro 6 - Proposta de drivers para mensurar os elementos realizáveis da Capacidade Absortiva

\begin{tabular}{|c|c|c|}
\hline $\begin{array}{c}\text { Elementos da } \\
\text { Capacidade absortiva }\end{array}$ & Transformação & Exploração \\
\hline $\begin{array}{c}\text { Drivers do Skandia } \\
\text { Navigator }\end{array}$ & $\begin{array}{l}\text { - Receita operacional líquida } \\
\text { - Receita/disciplina } \\
\text {-Despesas diretas do curso/despesas } \\
\text { administrativas } \\
\text { - Margem de Lucro } \\
\text { - Participação das vendas na pós-graduação da } \\
\text { instituição } \\
\text { - Número de clientes } \\
\text { - Número de clientes internos (alunos que são } \\
\text { funcionários da universidade) } \\
\text { - Número com desconto } \\
\text { - Número de clientes com desconto / número } \\
\text { de cliente } \\
\text { - Despesas administrativas/receita total } \\
\text {-Despesas administrativas/ professores } \\
\text { - Meta de qualidade corporativa (satisfação } \\
\text { dos alunos) } \\
\text { - Desempenho corporativo/meta de qualidade } \\
\text { - Custos anuais por aluno } \\
\text { - Custos diretos por aluno } \\
\text { - Número de professores } \\
\text { - Número de turmas } \\
\text { - Rotatividade dos professores por ano } \\
\text { - Número médio de anos de serviços com a } \\
\text { empresa }\end{array}$ & $\begin{array}{l}\text { - Investimento em TI } \\
\text {-Investimento no suporte aos alunos } \\
\text {-Investimento no treinamento de } \\
\text { alunos } \\
\text {-Participação no mercado interno } \\
(\%) \\
\text {-Índice de satisfação dos clientes (\%) } \\
\text {-Índice de motivação dos professores } \\
(\%) \\
\text {-Índice de investimento em } \\
\text { TI/receita total (\%) } \\
\text {-Índice de horas de treinamento (\%) } \\
\text { - Desempenho/meta de qualidade } \\
\text { (\%) } \\
\text { - Retenção dos empregados (\%) } \\
\text { - Despesas com o desenvolvimento } \\
\text { de competências/professor } \\
\text {-Índice de satisfação dos professores }\end{array}$ \\
\hline
\end{tabular}

Fonte: os autores

Com a mensuração dos drivers torna-se possível a mensuração dos elementos realizáveis da Capacidade Absortiva. Com os resultados desta mensuração, é possível qualificar os processos, rotinas e competências organizacionais. A teoria de Capacidade Absortiva prevê em seu escopo que altos níveis de transformação e exploração levarão a organização a vantagem competitiva.

Ao mensurar os drivers e identificar os focos do Skandia Navigator para os cursos de Pós-Graduação Lato Sensu, na modalidade a distância, imaginou-se ser possível a materialização dos resultados referentes ao capital intelectual desenvolvido nos cursos. A Capacidade Absortiva ajuda a explicar porque os cursospodem obter diferentes níveis de desempenho durante um determinado período de tempo.

\section{CONCLUSÃO}

A aceleração tecnológica e de costumes torna o mundo menos previsível. A generalização ou previsão indutiva sobre o futuro contém mais informação do que a soma de suas ocorrências particulares conhecidas. Assim as empresas, bem-sucedidas ou não, verificam o mesmo quadro de problemas, necessidades e expectativas. Isto ocorre, pois atuam no mesmo ambiente socioeconômico, incorrendo no impacto dos mesmos fatores estruturais ou conjunturais. Desta forma a medição e consequente avaliação do desempenho organizacional são importantes para o controle das ações.

Ferramentas de planejamento e controle são eficientes em momentos onde o cenário setorial está com excesso de oferta ou o acirramento entre os concorrentes é elevado. O cenário educacional não é muito diferente do descrito. Assim se considera adequado o uso do Skandia Navigator de maneira a planejar e controlar melhor as ações das instituições universitárias.

Além do mais, por ser uma ferramenta que se fundamenta no conceito de capital intelectual para articular recursos, capacidades e competências organizacionais, o Skandia Navigator foi utilizado para mensurar a capacidade absortiva da IES no tocante ao curso lato sensu Ead. Assim, o Skandinavia Navigator representa as áreas nas quais uma IES focaliza sua atenção, e de onde provém o valor de seu capital intelectual, os professores.

O navegador utilizado consistiu em trinta e um indicadores divididos em sete áreas, sendo indicadores financeiros;indicadores de cliente;indicadores de 
Autoavaliação e seus Drivers de Mudança Institucional Baseado na Capacidade Absortiva

processos;indicadores de renovação e desenvolvimento;indicadores humanos;capital intelectual; e eficiência do capital intelectual.

Como contribuição deste estudo, apresenta-se a proposta de drivers para mensurar os elementos realizáveis da Capacidade Absortiva. Pois entende-se que com a identificação destes drivers e elementos, torna-se possível almejar a vantagem competitiva. Este percurso até a vantagem competitiva,pode ser considerado mais consistente pois, tem-se uma proposta para mensurar as rotinas, processos $\mathrm{e}$ competências.

Como limitação a este estudo, destaca-se o número de cursos analisados, por não se tratar de uma IES por completo. Como proposta para estudos futuros, sugere-se a aplicação desta proposta em uma organização como um todo. É necessário também o levantamento te drivers para se mensurar os demais elementos da Capacidade Absortiva, bem como para os demais tipos de capacidades.

\section{REFERÊNCIAS}

Batista, M. A. et al (2013). Avaliação institucional no ensino superior: construção de escalas para discentes e docentes. Avaliação (Campinas), 18.

Capron, L. \& Mitchell, W. (2008). Selection capability: how capability gaps and internal social frictions affect internal and external strategic renewal. Organization Science, 19, 1-19.

Cohen, W. M. \& Levinthal, D. A (1990). Absorptive Capacity: A New Perspective on Learning and Innovation. Administrative Science Quarterly, 35, $128-152$.

Crispim, S. \& Lugoboni, L. (2012). Avaliação de desempenho organizacional: Análise comparativa dos modelos teóricos e pesquisa de aplicação nas Instituições de Ensino Superior da Região Metropolitana de São Paulo. Rev. Portuguesa e Brasileira de Gestão, 11.

Edvinsson, L \& Malone, M. S (1998). Capital intelectual. São Paulo: Makron Books.

Frederico, G. F. \& Martins, R. A. (2012). Modelo para alinhamento entre a maturidade dos sistemas de medição de desempenho e a maturidade da gestão da cadeia de suprimentos. Gest. Prod., 19.

Flatten, T. C., et al. (2011). A measure of absorptive capacity: Scale development and validation. European Management Journal, 29, 98-116.

Fosfuri, A. \& Tribó, J. A (2008). Exploring the antecedents of potential absorptive capacity and its impact on innovation performance. Omega, 36,173187.

Gray, C. (2006). Absorptive capacity, knowledge management and innovation in entrepreneurial small firms.International Journal of Entrepreneurial Behaviour\& Research, 12, 345360.

Hourneaux Junior, F (2005). Avaliação de desempenho organizacional: estudo de casos em empresas do setor químico. Dissertação de mestrado em Administração, USP, São Paulo.

Jansen, J.J.P. \& Van Den Bosch, F.A.J. \& Volberda, H.W. (2005) Managing potential and realized absorptive capacity: How do organizational antecedents matter?, Academy of Management Journal, 48, 999-1015.

Kor, Y. Y. \& Mesko, A. (2013). Dynamic managerial capabilities: configuration and orchestration of top executives' capabilities and the firm's dominant logic. Strategic Management Journal, 34, 233-244.

Lane, P. J. \& Koka, B. R. \& Pathak, S. (2002). The reification of absorptive capacity: a criticalreview and rejuvenation of the construct. Academy of Management Review, 31, 833-863.

Lehfeld, N. A. de S., et al (2010). Reflexões sobre o processo de autoavaliação institucional: o olhar de uma comissão própria de avaliação. Avaliação (Campinas), 15.

Lichtenthaler, U. (2009). Absorptive capacity, environmental turbulence, and the complementarity of organizational learning processes. Academyof Management Journal, 52, 822-846.

Lichtenthaler, U. \& Lichtenthaler, E. (2009) .Capability-Based Framework for Open Innovation. Journalof Management Studies, 46.

Lima, C. R. M. \& Soares, T. C. \& Lima, M. A. (2012). Utilização do BalancedScorecard em Instituições de Ensino Superior. RIC - Revista de Informação Contábil. 6, 1-13.

Lima, M. A. \& Soares, T. C. \& Lima, M. V. A. \& Lima, C. R. M. (2013). Autoavaliação de instituições de educação superior: Exame de dificuldades organizacionais e gerenciais. REID, $10,21-42$.

Lima, A. \& Carmona, C. (2011). Determinantes da formação do capital intelectual nas empresas produtoras de tecnologia da informação e comunicação. Revista de Administração Mackenzie, 12, 112-138. 
Maba, E. G. \& Marinho, S.V. (2012). A autoavaliação institucional no processo de tomada de decisão em IES: estudo de caso das Faculdades SENAC/SC. Avaliação (Campinas), 17.

Malavski, O. S. \& Lima, E. P. \& Costa, S. E. G. (2010). Modelo para a mensuração do capital intelectual: uma abordagem fundamentada em recursos. Prod. 20, 439-454.

Meyer Jr. V. \& Meyer, B. (2004). Planejamento estratégico nas instituições de ensino superior: técnica ou arte? In:IV Colóquio Internacional sobre Gestão Universitária na América do Sul, Universidade Federal de Santa Catarina - UFSC, Florianópolis, 8-10.

Murovec, N. \& Prodan, I. (2009). Absorptive capacity, its determinants, and influence on innovation output: Cross-cultural validation of the structural model. Technovation, 17.

Nascimento, S. et al. (2011). Mapeamento dos indicadores de desempenho organizacional em pesquisas da área de Administração, Ciências Contábeis e Turismo no período de 2000 a 2008. Rev. Adm. (São Paulo), 46, 373-391.

Ng, D. W. (2007). A Modern Resource Based Approach to Unrelated Diversification. Journal of Management Studies, 44.

Rothaermel, F. T. \& Alexandre, M. T. (2009). Ambidexterity in Technology Sourcing. Organization Science, 20, 759-780.

Samia, A., et al (2012).Comparative study, based on metamodels, of methods for controlling performance. IJCSI International Journal of Computer Science Issues, 9.
Soares, T. C., et al (2012). Modelo de planejamento e controle gerencial para educação a distância. $R$. Adm. FACES Journal, 11, 158-174.

Teece, D. J. \& Pisano, G. \& Shuen, A. (1997) Dynamic Capabilities and Strategic Management. Strategic Management Journal, 509-533.

Vargas, V. do C. C. de \& Selig, P. M. \& Andrade, D. F. De \& Ribeiro, J. L. D. (2008). Avaliação dos intangíveis: uma aplicação em capital humano. Gest. Prod., 15.

Versiani, Â. F., et al. (2010) Mensuração da Capacidade Absortiva: até que ponto a literatura avançou? XXXIV Enanpad, Rio de Janeiro.

Viedma Marti J. M. (2007). In Search of an Intellectual Capital Comprehensive Theory. The Electronic Journal of Knowledge Management, 5, 245 - 2567.

Von Krogh \& Ichijo \& Nonaka. (2001) Facilitando a criação do conhecimento: reinventando a empresa com o poder da inovação contínua. Rio de Janeiro: Campus.

Wang, C. L. \& Ahmed, P. K. (2007). Dynamic capabilities: A review and research. International Journal of Management Reviews, Oxford, 9, p. 3151.

Wegner D. \& Maehler, A. E. (2012). Desempenho de empresas participantes de rede interorganizacionais: analisando a influência do capital social e da capacidade absortiva. Revista Gestão $e$ Planejamento, 13, 191-211.

Zahra, S.A. \& George, G. (2002). Absorptive Capacity: A Review, reconceptualization, and extension. Academy of Management Review, 27, 185-203. 